\title{
A Grammatical Description of Leteh Nominal Morphology
}

\author{
Mercy Akrofi Ansah \\ University of Ghana
}

\begin{abstract}
The paper describes Leteh nominal morphology within the framework of Basic Linguistic Theory (Dixon 2010; Dryer 2006). The nominal morphology is described in the context of two phenomena: number marking and noun classification. Leteh is a South-Guan language from the Niger-Congo family of languages. The morphology of Leteh is largely agglutinative. Güldemann and Fiedler (2019) argue that current analyses of gender systems are heavily influenced by those in Bantu languages and not cross-linguistically applicable. They propose an alternative analysis that includes the notions agreement class and nominal form class. In this paper I adopt the notion of nominal form class to classify nouns in Leteh. The nouns are grouped into four major classes based on the plural morphemes that they take. These classes are subdivided based on the singular forms with which they are paired.
\end{abstract}

Keywords: Leteh, nouns, morphology, classification, nominal form class, affixes

\section{Introduction}

In this paper we discuss the nominal morphology of Leteh, a less-studied language spoken in Ghana, with a focus on the classification of nouns. The issue of what constitutes a noun class has been contested in the literature, and the Kwa languages, to which Leteh belongs, have also witnessed such debate. For instance, while Osam $(1993,1994)$ argues that Akan used to have a noun class system but synchronically it is only left with the vestiges of the system, Bodomo and Marfo argue that it still has a robust system. Güldemann and Fiedler (2019) argue that traditional analysis is heavily influenced by the agreement system that occurs in Bantu languages. This is where nominal affixes systematically align with agreement patterns. While some Kwa languages, especially Ghana-Togo-Mountain (GTM) languages, exhibit this type of agreement, most do not. Leteh does not have the kind of robust system that exists in Bantu languages. Instead, noun modifiers agree with the head noun in number. In this paper, I use the notion of nominal form class proposed by Güldemann and Fiedler to analyse these nouns.

The rest of the paper is structured as follows: in section 1.1, I provide an overview of Leteh. Section 2 discusses the methodology and theoretical framework of the study. In section 3, I discuss number marking strategies and the classification of nouns into nominal form classes. Section 4 concludes the paper.

1.1 An overview of Leteh. Leteh is spoken in a single town in the southeast of Ghana called Larteh. Speakers call the language Leteh but in the literature and elsewhere, it is spelt Larteh or Lat $\varepsilon$. In this paper, I refer to the language as Leteh and reserve the name Larteh for the place 
where it is spoken. Eberhard, Simons and Fennig (2019) classify Leteh as South Guan ((Kwa, Niger-Congo) http://www.ethnologue.com/.

Leteh has four dominant set A vowel phonemes /i, e, o, u, / and five set B phonemes /I, $\varepsilon$, $\supset, v, a /$. Vowels of set A are produced with an advanced tongue root [+ATR], whereas those belonging to set B are produced with a retracted tongue root [-ATR]. In Leteh, vowels in a word of two or more syllables share the [ATR] feature. Evidence of this tongue-root harmony principle is observed in the allomorphs of the tense/aspect morphemes which mark the future tense, the progressive and the perfect aspects. These are $b \grave{e}-/ b \dot{\varepsilon}-$, $d \dot{i}$-dí- and yé-/yć- respectively. There are exceptions to the harmony principle. The low vowel /a/ can occur in the final syllable of roots that have advanced vowels. Examples are kpirenya 'fist', osia 'parent in-law' and okonkura 'pepper'. However, where /a/ precedes +ATR vowels either as a prefix or the initial vowel of a bisyllabic

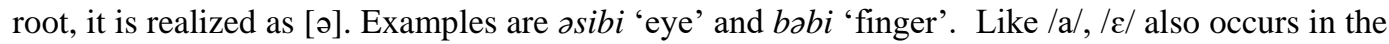
final syllable of some roots that have advanced vowels. Examples are obitew 'uncle' and ofure 'farm' (see Akrofi Ansah 2009: 59-60; 2015/16: 99).

Leteh does not have an official orthography. As a result, the few studies that have been conducted on the language have used the Akan orthography, specifically that of Akuapem Twi which is based on the seven vowels shown in (1).

$$
\text { /i, e, } \varepsilon, \text { o, o, u, a/ }
$$

The consonant inventory of Leteh includes the labial-velar plosives, $/ \mathrm{kp}, \mathrm{gb} /$, as shown in the words in (2). Although consonant clusters are rare, a few syllable and word-initial nasal clusters like $/ n k, m f, n t /$ are identified (3). The preferred syllable structure is $\mathrm{CV}$, an indication of an open-syllable language.

\begin{tabular}{|c|c|c|c|c|}
\hline $\begin{array}{l}/ \mathrm{kp} / \\
/ \mathrm{gb} /\end{array}$ & $\begin{array}{l}\text { mkpa } \\
\text { əgbeli }\end{array}$ & $\begin{array}{l}\text { 'bed' } \\
\text { 'cassava' }\end{array}$ & $\begin{array}{l}\text { okp } \varepsilon \\
\text { dwogbuni }\end{array}$ & $\begin{array}{l}\text { 'road' } \\
\text { 'vulture' }\end{array}$ \\
\hline$/ \mathrm{nk} /$ & nkre & 'blood' & Nkra & 'Accra city' \\
\hline hf/ & mfra & 'salt' & $\mathrm{mfl}, \mathrm{mfa}$ & 'here, there' \\
\hline$/ \mathrm{nt} /$ & ntebi & 'things' & nt $\varepsilon$ & 'strong drink' \\
\hline
\end{tabular}

Leteh is a register tone language with two level tones, Low and High, which are shown in examples (4a) and (4b) respectively. It also has the High-Low falling contour tone, as illustrated with the words in (5a), and rare instances of words with Low-High rising tone, as shown in (5b) (Akrofi Ansah 2009: 65-66). The lexical tone helps to distinguish meanings of words which otherwise are the same in terms of their constituents (5a). The grammatical tone, coupled with verbal prefixes, is employed in making tense and aspectual distinctions (6).
a. nù 'drink'
nyò 'switch on'
ǹkìrè 'message'
b. nú 'meat'
nyó 'two'
ńkíré 'blood'
a. ébî' 'seed'
ódó' 'car/machine'
kémì 'rib'


b. h̆̌ 'yes, okay'
a. Kofi
wòsù
nte.
Name
PRES.wake up early
'Kofi wakes up early.'
b. Kofi wósù nte.
Name PST.wake up early
'Kofi woke up early.'

Akin to the majority of Kwa languages, the morphology of Leteh displays agglutinating features. Case is not marked in the language, constituent order therefore marks grammatical relations. An unmarked Leteh clause has AVO and SV order and syntax (7).

$$
\begin{array}{lll}
\text { Ama } & \text { dítwú } & \text { [ayirebi a] } \\
\text { S/A } & \mathrm{V} & \mathrm{O}
\end{array}
$$

'Ama is a child.'

Major word classes include nominal, verbal, adjectival and adverbial classes. Leteh nouns express number concord with their modifiers. Consequently the nouns are assigned to classes based on identical singular and plural prefixes. The nominal class is open, and processes like reduplication, compounding and tonal change are notable ways by which the class is augmented (Akrofi Ansah 2009, 2012a, 2012b). Gerundive nouns that express activities, for instance, are the products of compounding and tonal change. Examples of gerundive nouns derived through synthetic compounding are ètèfó 'washing' and lètsú 'singing'. While ètè-f́' 'washing' is constituted by the noun, été 'thing' and fò 'wash', lè-tsú 'singing' is from lè 'song' and twù 'sing'. An example of a noun derived from a verb by tonal change is the verb fìtśs 'sweep' which becomes fótsì 'sweeping'. It must however be noted that the context of their use often plays a crucial role in distinguishing between a gerundive nominal that is derived by tonal change and a verb because the tone patterns could resemble that of the tense and aspectual form of the verb.

In contrast to the class of nouns, no process has yet been identified which derives verbs. The class of underived adjectives, all monomorphemic, numbers 13, whilst the majority of adjectives are derived from nouns and verbs. The class of underived adjectives may be categorized based on semantics: dimension, color, age and value. Although the majority of the adjectives display prefixes, it has not been possible to classify them by morphological features (Akrofi Ansah 2013). Adverbs are mostly derived from adjectives through partial and complete reduplication of adjective stems.

Available data on Leteh demonstrate that both prepositions and postpositions operate in Leteh grammar. Negation is marked through the prefixation of the main verb of a clause.

A simple noun phrase in Leteh has the following structure: $\mathrm{NP} \rightarrow \mathrm{N}$ (ADJ) (QT/NUM) (DET), where the head noun precedes all modifiers and all modifiers are optional (8) (Akrofi Ansah 2014).

$$
\begin{aligned}
& \text { a-yirebi (o-tonto) } \quad \text { (a). } \\
& \text { SG-child PL-tall DEF } \\
& \text { 'The tall child'. }
\end{aligned}
$$



b. N-yirebi (n-tonto) (sa) (a).
PL-child PL-tall three DEF
'The three tall children'.

Sentences ( $8 \mathrm{a}$ and $8 \mathrm{~b}$ ) show that the adjective agrees with the noun in number. Some nouns do not take any prefix. For such nouns, it is the adjective that determines whether it is singular or plural. It should be mentioned here that while adjectives agree in number with the noun, they do not agree in class. This means that a noun in the singular will be modified by the same form of singular adjective, no matter its class. The same applies to plural nouns

In table 1, we show the underlying forms of personal pronouns in Leteh. It is noted that there is no distinction based on the class of a noun. Instead, Leteh pronouns make animacy distinctions in the third person.

Table 1. Underlying forms of person markers in Leteh

\begin{tabular}{|c|c|}
\hline PERSON & SUBJECT PRONOMINALS \\
\hline $1 \mathrm{SG}$ & $N-$ \\
\hline $2 \mathrm{SG}$ & $w v^{\prime}$ \\
\hline $3 \mathrm{SG}$ & $a ́$ (animate) $/ i$ (inanimate) \\
\hline $1 \mathrm{PL}$ & غ̀ní \\
\hline $2 \mathrm{PL}$ & wónć \\
\hline 3PL & ámó (animate)/ $i$ (inanimate) \\
\hline Generic & $\dot{E}-$ \\
\hline
\end{tabular}

It can be observed that the inanimate pronoun is $i$ for both singular and plural entities.

\section{Methodology and Framework}

The paper is purely descriptive, and it employed a fieldwork based approach in collecting data. The SIL Comparative African Wordlist (Snider \& Roberts 2004) was used; a cross-section of the speech community was selected to produce the Leteh versions of the words on the list. In all, 24 consultants were engaged, consisting of the following age groups: 12-18; 19-30; 31-45; 46 and above. Elicitation sessions were held with the consultants where they produced Leteh equivalents of the nouns contained in the wordlist. The data are made up of forms which are most common and accepted by the most competent native speakers who usually are those who have lived in the speech community for the greater part of their lives. Audio recordings of the elicitation sessions were done after which transcription, and analyses of the elicited nouns were carried out.

Tenets of the Basic Linguistic Theory (hereafter, BLT), a cumulative framework, which is informed by functional, formal, structural and typological insights were appealed to. This is a cumulative framework within which many descriptive grammars are cast, and have exploited the advantage of describing a language in its own terms, rather than imposing concepts whose primary motivation comes from other languages in contrast to traditional grammar and many recent theoretical frameworks (Dixon 2010; Dryer 2006). 


\section{Leteh Nominal Morphology}

The paper aims to describe the morphology of Leteh nouns. As already stated, the language exhibits agglutinating features; it is mostly prefixal and in a few cases, with regard to kinship and social relations' terms, suffixes are also used to express plurality.

3.1 Number Marking. With respect to number marking ${ }^{1}$, nouns in Leteh may be categorized into two broad groups. The first group is constituted by nouns that are neutral with regard to the inflectional category of number; their forms refer to a single entity or two or more entities. These nouns are provided in Tables $2 \mathrm{a}$ and $2 \mathrm{~b}$. Table $2 \mathrm{~b}$ comprises gerundive nouns that are derived through compounding (i.e., vii) and tonal change (i.e., viii) (Akrofi Ansah 2009, 2012a, 2012b). The second group consists of nouns which may be marked for number. In Table $2 c$, we illustrate the different ways in which nouns in this group inflect for number. In their citation form, a Leteh noun may occur with or without a prefix. The prefixes are vowels or a syllabic nasal which is always homorganic with the initial consonant of the stem. ${ }^{2}$

Table 2a Leteh nouns and number marking

\begin{tabular}{|c|c|c|c|}
\hline Groupings & Affixes & Examples & Gloss \\
\hline i. & $\varnothing$ & $\phi$-site & ground \\
\hline ii. & $\mathrm{N}-$ & $m-k p \varepsilon$ & life \\
\hline iii. & o-/a- & $a-l$ ItI & evening \\
\hline iv. & o-/ $/$ & $o-h a w$ & trouble \\
\hline v. & $\mathrm{e}-/ \varepsilon-$ & $e-s e$ & matter \\
\hline vi. & i-/I- & $I-k \tilde{J}$ & war \\
\hline
\end{tabular}

Table 2b Gerundive nouns and number marking

\begin{tabular}{|c|c|c|c|}
\hline Groupings & Example & Gloss \\
\hline vii. & & ètèf'́ & washing \\
\hline & & lètsú & singing \\
\hline & & ètèbá & sewing \\
\hline viii. & & tsá & dancing \\
\hline & & bì̀ & bathing \\
\hline & & fótsì & sweeping \\
\hline
\end{tabular}

\footnotetext{
${ }^{1}$ Lists of nouns illustrating number marking phenomena are given under section 3.2 of this paper.

${ }^{2}$ In Tables 2a and 2c, a slash between two vowels indicates a variation based on the [ATR] specification of the vowel in the first syllable of the host.
} 
Table 2c Leteh nouns and number marking

\begin{tabular}{|c|c|c|c|c|c|}
\hline \multirow[t]{2}{*}{ Groupings } & \multicolumn{2}{|r|}{ Affixes } & \multicolumn{2}{|c|}{ Example } & \multirow[t]{2}{*}{ Gloss } \\
\hline & SG; & PL & SG & PL & \\
\hline ix & $\varnothing-;$ & $\mathrm{e}-/ \varepsilon$ & $\phi$-nimi & $e-n i m i$ & teeth \\
\hline $\mathrm{x}$ & $\emptyset-;$ & $\mathrm{N}-$ & $\phi$-kuro & n-kuro & towns \\
\hline $\mathrm{xi}$ & ə-/a-; & $\mathrm{N}-$ & a-we & $n$-we & calabash \\
\hline xii & o-/o-; & $\mathrm{e}-/ \varepsilon-$ & $o$-bisi & $e$-bisi & cola nuts \\
\hline xiii & o-/o-; & $\mathrm{e}-/ \varepsilon-,-\varepsilon n \varepsilon$ & $\begin{array}{l}o-n i \\
o-S I\end{array}$ & $\begin{array}{l}e-n i-\varepsilon n \varepsilon \\
\varepsilon-S I-\varepsilon n \varepsilon\end{array}$ & $\begin{array}{l}\text { mothers } \\
\text { fathers }\end{array}$ \\
\hline xiv & o-; & a- & o-korI & $a-k J r I$ & eagles \\
\hline
\end{tabular}

As previously stated, number marking is irrelevant for nouns in Tables $2 \mathrm{a}$ and $2 \mathrm{~b}$. We shall now turn our attention to nouns in Table $2 \mathrm{c}$ which distinguish morphologically between singular and plural. Nouns in this group can be sub-grouped into those that take prefixes and those that do not. For the purposes of this paper, we shall treat nouns without prefixes as having a $\emptyset$ prefix. In Table $2 \mathrm{c}$ nouns in this sub-grouping occur in (ix and $\mathrm{x}$ ). They are subdivided into two groups because they inflect for plurality in two ways: the first sub-group (ix) selects $e-/ \varepsilon$ as a plural prefix whereas the second sub-group (x) selects a homorganic nasal, $N$-, to index plurality. Available data suggest that nouns in (x) are mostly Akan loan words (see Table 4a). Members of the second sub-grouping have overt prefixes in the singular and plural. Nouns in sub-group (xi) display $\partial-/ a$ - prefixes in their singular form, and the homorganic nasal, $/ N-/$ as a plural prefix. Nouns which belong to sub groups (xii) and (xiii) have $o-/ 3$ as singular prefixes and index plurality by selecting $e-/ \varepsilon$. Additionally, nouns in sub-group (xiii), which are principally kinship and social relations' terms, are suffixed by the morpheme $/-\varepsilon n \varepsilon /$. The suffix vowels remain unadvanced even when the stem has advanced vowels.

The plural kinship terms are used when a speaker is referring to more than one person in both formal and informal settings. In a formal setting, a speaker may address a group which is

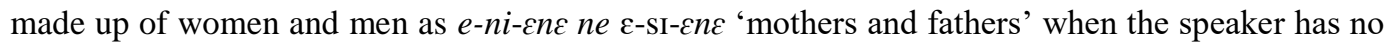
blood relations with the addressees. The plural kinship terms also apply to one's biological mother and her sisters, who in Leteh culture are also called mother since there is no title for one's mother's sister, what in English is known as aunt.

Nouns belonging to group (xiv) are mostly Akan loan words. In their singular form, they are prefixed with $っ$ - and they signal plurality by the prefix $a$-. In section 3.2 of this paper, we list examples of nouns and patterns of number marking. We proceed to categorize the nouns into nominal form classes, based on number agreement patterns.

3.2 Classification of Leteh Nouns. There is some disagreement in the literature on the appropriate way to classify nouns, and this disagreement shows up in the classification of nouns in Kwa languages. For instance, based on morphological, morpho-syntactic and semantic reasons, Osam (1993, 1994), argues that the synchronic nominal prefixes of Akan are the vestiges of a previous productive noun class system. He goes on to assert, however, that modern Akan does not have a functioning noun class system nor a concordial system. A similar remark is made by Broohm (2017) about Esahie, another Kwa language. Bodomo \& Marfo (2006) however disagree with Osam's (1993) assertion that Akan does not have a noun class system synchronically. They argue that number -singular and plural - is "the most appropriate criterion that can be used to set up noun classes" in Akan (and Dagaare, a Gur language). They add that "[concord] marking [...] 
is not a very sufficient criterion as is number" Bodomo \& Marfo (2006: 206). Like Akan, Guan languages in general, also do not exhibit concord. An important fact is also that the phenomenon differs across languages. For instance, in contrast to languages like Akan and Leteh, other Kwa languages such as Tutrugbu (Essegbey 2009) and Selec (Agbetsoamedo 2014) which belong to the Ghana-Togo-Mountain (GTM) group have been found to display not only nominal prefixes but also agreement classes similar to those pertaining to Bantu languages.

The Kwa languages exhibit a problem in the analysis of noun classes that has been pointed out by Güldemann \& Fiedler (2019) who argue that the Niger-Congo concept and term 'noun class' is 'highly problematic' (2017: 113). They point out that the term has come to bear different meanings in Niger Congo studies, and depends on diverse language-specific situations, thereby creating confusion in noun classification. While the term assumes that there is a systematic one-to-one mapping between nominal form classes and agreement classes, this does not always apply for those who use the term. Further, Güldemann and Fiedler note that the analytic tool that underpins the noun-class concept is not cross-linguistically applicable. They therefore propose a new tool that includes such notions as agreement class and nominal form class. In this paper, we adopt the term nominal form classes in categorizing Leteh nouns. Number marking patterns of Leteh nouns enable us to assign them to nominal form classes. Leteh does not have a concordial system based on the nouns. Similar to a significant number of Kwa languages, and as argued by Osam for Akan, the Leteh nominal form class system may be described as one with traces of perhaps a once productive nominal form class system.

In this paper, our use of the term nominal form class draws on, and modifies, Schuh (1995) characterization of one way in which noun classes used to be analysed. That is to say a nominal form class refers to a paired set of prefixes where one member of the pair has a singular referent and the other member of the pair is the plural corresponding to that singular. Consequently, the defining criterion for the classification of Leteh nouns is based on similarity in plural affixes borne by the noun. Nouns that have similar plural markers are grouped together in the same class. They are then sub-divided according to whether they have similar singular prefixes. Going by the said criterion, we categorize Leteh nouns into 4 broad nominal form classes: I, II, III, IV, identified by plural prefixes: $\emptyset_{-;} ;-; e-/ \varepsilon ; a-$. Within each broad class, we identify singular prefixes that may differ morphologically; consequently, 11 nominal form classes are obtained made up of 11 singular and plural pairings (Tables 3-6). As we proceed, it will be demonstrated that Leteh nominal prefixes do not correspond to meaning distinctions. It is therefore difficult to predict the membership of nouns within one or the other class using semantic criterion. In the following subsections we discuss the different nominal forms classes and some nouns that occur in them.

3.2.1 Class I. Nouns in Class I (Table 3) do not distinguish between singular and plural. Within the class, there are six subclasses (a-f); with the exception of the members of subclass (a), each subclass bears a distinct prefix. 
Table 3 Leteh Nominal form Class I

\begin{tabular}{|c|c|c|c|c|}
\hline Class I ø- & Examples & Gloss & Examples & Gloss \\
\hline a. $\varnothing-$ & $\phi$-bəbi; & 'finger' & $\phi$-letsu & singing \\
\hline b. N- & $m-k p \varepsilon$ & life & n-tsu & water \\
\hline c. & ә-pi; & heart & a-nv & mouth \\
\hline d. $\quad 0-/ \mathrm{o}$ & $o-l u$; & medicine & o-detI & metal \\
\hline e. $\mathrm{e}-/ \varepsilon$ & $e-f u$ & wind & $\varepsilon-h v t s$ & mud \\
\hline f. $\quad \mathrm{i}-/ \mathrm{I}$ & i-gyesu; & smoke & $I-k o$ & war \\
\hline
\end{tabular}

Words which occur in subclass Ia do not bear any prefix; an example is bəbi 'finger'. In examples (9a-c), we illustrate number agreement with attributive and predicative adjectives:
a. Kofi mo
bəbi a-kitibi.
PN 3SG.POSS SG.finger SG-small
'Kofi's small finger.'
b. Kofi mo bəbi gyí a-kitibi PN 3SG.POSS SG.finger COP.be SG-small 'Kofi's finger is small.'
c. Kofi mo bəbi [n-kitibi] [n-kitibi]. PN 3SG.POSS SG.finger PL-small PL-small 'Kofi's small fingers.'

Example (9c) shows that when nouns in subclass (a) occur with adjectives in plural form, they do not exhibit any number prefix. The nouns are modified by a reduplicated form of the plural adjective to express plural sense. This is applicable to all the nouns in Class I. The difference is that nouns in subgrouping (b-f) have prefixes.

It should be pointed out that it is not all nouns in subclass Ia that can be modified by the plural form of an adjective. An example is the locative nominal site 'ground', which, as shown in (10b), cannot be modified by a the plural adjective. This is doubtless because of the semantics of site 'ground':
a. site kpotii.
ground big
'big/large ground'
b. *site [m-kpoti][m-kpotii].
Ground PL-big PL-big
'big/large grounds.'

In Table (3a) we list nouns which belong to the subclass. The subclass is mostly constituted by body part nouns. 
Table 3(a) ø- prefix

\begin{tabular}{|l|l|}
\hline SG/PL & Gloss \\
\hline sise & body/person \\
\hline bambaas & shoulder \\
\hline fite & throat \\
\hline kvna & neck \\
\hline fã & larynx \\
\hline potwo & testicle \\
\hline korl & vagina \\
\hline bakvna & wrist \\
\hline kpirenya & fist \\
\hline babi & finger \\
\hline site & ground \\
\hline
\end{tabular}

Nouns belonging to subgroup Ib bear an $N$-prefix, for example, $n$-wu 'head'. From (11ac), we illustrate their agreement patterns with adjectives.
a. Kisı
a mo
n-wu
a-kitibi.
monkey DEF 3SG.POSS SG/PL-head SG-small

'The monkey's small head.'

b. Kisı a mo n-wu gyí a-kitibi. monkey DEF 3SG.POSS SG/PL-head COP.be SG-small 'The monkey's head is small.'
c. N-kisı a amo
n-wu
[n-kitibi] [n-kitibi].
monkey DEF 3PL.POSS SG/PL-head PL-small PL-small
'The monkeys' small heads.'

The examples show that the nasal prefix does not change even when the adjective receives a plural marker. In Table 3(b), we list the nouns in this subclass. They are mostly bodypart nouns.

Table 3 (b) N-prefix

\begin{tabular}{|l|l|}
\hline SG/PL & Gloss \\
\hline$m-k p \tilde{\varepsilon}$ & life \\
\hline$n$-yepi & jaw \\
\hline$n$-kyini & muscle \\
\hline$n$-kre & blood \\
\hline$n$-wu & head \\
\hline$m$-inc & hair \\
\hline$n$-sanaba & upper arm \\
\hline$n$-yoobi & maggot \\
\hline$n$ - $d a$ & ants \\
\hline$m-f o t l$ & termite \\
\hline
\end{tabular}


We move to subclass Ic where the nouns have $ə-/ a$ - prefix. An example of nouns in this class is adanda 'cheek'. The behavior of adjectives with this subclass is not different from the ones discussed earlier, as shown by (12a, b \& c).
a. Ama mo
a-danda
ə-kitibi.

PN 3SG.POSS SG/PL-cheek SG-small

'Ama's small cheek.'

b. Ama mo a-danda gyí ə-kitibi.

PN 3SG.POSS SG/PL-cheek COP.be SG-small

'Ama's cheek is small.'

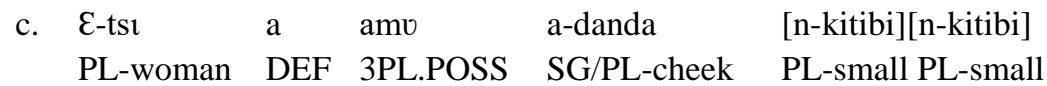

'The women's small cheeks.'

It is observed that the Ic subclass is mostly constituted by mass nouns and body part names as illustrated in Table 3 (c).

Table 3(c) $\partial-/ a$ prefix

\begin{tabular}{|l|l|}
\hline SG/PL & Gloss \\
\hline o-denebi & forehead \\
\hline -sibite & face \\
\hline o-sibi & eye \\
\hline$a$-hvnv & nose \\
\hline$a$-danda & cheek \\
\hline$a-n v$ & mouth \\
\hline$a-n v f a f a$ & lips \\
\hline$a-k v r \varepsilon m \varepsilon$ & nape of neck \\
\hline o-kuminc & beard \\
\hline o-ku & chin \\
\hline
\end{tabular}

Nouns in the Id subclass have the $o$ - $\supset$ - prefix. An example is -detl 'iron'. Although we have chosen a different adjective here, it is important to note from examples (13a-c) that the attributive and predicative forms of the adjectives behave the same way with these verbs as they do verbs in the preceding subclasses. From Table 3(d), it is noticeable that the nouns do not share any semantic feature.
a. $\quad$-detı
--timi
a.
SG/PL-iron SG-short DEF
'The short iron (piece).'
b. o-detı a gyí ə-timi. SG/PL-iron DEF COP.be SG-short 'The iron (piece) is short.' 
c. o-detı n-timi n-timi a

SG/PL-iron PL-short PL-short DEF

'The short iron (pieces).'

Table 3(d) o-/o- prefix

\begin{tabular}{|c|c|}
\hline SG/PL & Gloss \\
\hline o-hv & breast \\
\hline$o-k \tilde{\varepsilon}$ & frontier \\
\hline o-kpvkpv & wall \\
\hline o-don & bell \\
\hline 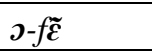 & broom \\
\hline o-dectl & iron \\
\hline o-tvba & tobacco \\
\hline
\end{tabular}

Nouns in subclass Ie have $e-/ \varepsilon$ as prefix. An example is $e$-bi 'seed'. Examples (14a-c) show that attributive and predicative adjectives agree with the noun in number. Sentence (14c) shows that unlike the preceding adjectives, hue is not reduplicated in the plural.

a. E-bi o-hue.

SG/PL SG-new

'New seed.'

b. E-bi a gyí o-hue.

SG/PL DEF COP.be SG-new

'The seed is new.'

c. E-bi e-hue.

SG/PL PL-new

'new seeds.'

Nouns belonging to subgroup Ie are predominantly non-count nouns and food crops; they are given in Table $3 \mathrm{e}$.

Table 3 (e) $e$-/ $\varepsilon$ - prefix.

\begin{tabular}{|l|l|}
\hline SG/PL & Gloss \\
\hline$e$-kpunii & okra \\
\hline$e-k p \tilde{u}$ & egg plant \\
\hline$e$-tsuru & mushroom \\
\hline$e-b i$ & seed \\
\hline$\varepsilon-m v$ & rice \\
\hline$e-b e$ & palm-nut \\
\hline$e-b i \tilde{\varepsilon}$ & lice \\
\hline$e-b i t e$ & voice \\
\hline$e-s i$ & horn \\
\hline
\end{tabular}


The last subgroup of Class I comprises nouns with an $i$-/I- prefix. An example is $l$ - $t \tilde{\boldsymbol{a}}$ 'cloth'. When the noun denotes a plural entity, the form of the noun remains the same but the adjective is expressed in the plural. That is to say the singular prefix $っ$ - in $っ$-dId $\varepsilon$ - 'old', changes to $\varepsilon$ - in $\varepsilon$-dide 'old'. (15c).

a. $\quad$-tã o-dide.

SG/PL-cloth SG-old

'old cloth.'

b. 1-tã a gyí o-dide.

SG/PL-cloth DEF COP.be SG-old

'The cloth is old.'

c. i-tã $\quad \varepsilon$-did $\varepsilon$.

SG/PL-cloth PL-new

'old cloths.'

Table 3(f) i-/l- prefix

\begin{tabular}{|c|c|}
\hline SG/PL & Gloss \\
\hline$l-t \tilde{\boldsymbol{a}}$ & cloth \\
\hline$i-f \tilde{\boldsymbol{u}}$ & fear \\
\hline$i$-gyesu & smoke \\
\hline$i-h i$ & rubbish \\
\hline$l-k \tilde{\boldsymbol{D}}$ & war \\
\hline
\end{tabular}

Nouns in subclass If are predominantly non-count nouns.

In sum, nouns in Class I have the same form in singular and plural. This is irrespective of whether the noun occurs with a prefix (as in subclasses Ib-If) or without a prefix (as in subclass Ia). Because the adjectives with which they occur agree with them in number, they help to determine whether the nouns denote singular or plural entities.

3.2.2 Class II. We now turn our attention to Leteh nominal form class II (Table 4) which is subcategorized into two. The distinguishing feature of this class is its common plural agreement marker, $N$-.

Table 4 Leteh nominal form Class II

\begin{tabular}{|cl|l|l|l|}
\hline Class II N- & Singular & Gloss & Plural \\
\hline a. $\varnothing-;$ & N- & $\phi$-kuro & town & $n$-kuro \\
b. $\quad$--/a-; & N- & a-we & calabash & $n$-we \\
\hline
\end{tabular}

Whereas the first subclass (IIa) is identified by the singular prefix $\emptyset$-, members of the second subclass (IIb) have the singular prefix, a-/a-. An example of nouns in subclass IIa is kuro 'town'. Sentences_(16a and 16b), on the one hand, and (16c), on the other, show that the form of the noun as well as the adjective changes when they change from singular to plural. In the case of the noun, the change is from prefix-less to taking a ə-/a-prefix. 
(16)

a. $\varnothing$-kuro o-hue o-ko.

SG-town SG-new SG-INDEF

'(a) new town'.

b. $\varnothing$-kuro a gyi o-hue.

SG-town DEF COP.be SG-new

'The town is new'.

c. n-kuro e-hue n-ko.

PL-town PL-new PL-INDEF

'Some new towns.'

Table 4a, contains examples of nouns of subclass IIa.

Table 4a. ø-; N-

\begin{tabular}{|l|l|l|}
\hline Singular & Gloss & Plural \\
\hline pretı & plate & m-pretl \\
\hline kankyıl & bowl & $n$-kankyll \\
\hline kotoku & sack & $n$-kotoku \\
\hline kenten & basket & $n$-kenten \\
\hline paant & needle & m-paanı \\
\hline dadıwa & nail & $n$-dadlwa \\
\hline kuro & town & $n$-kuro \\
\hline kontimaa & cudgel & $n$-kontimaa \\
\hline kwaakwaadabi & crow & $n$-kwaakwaadabi \\
\hline
\end{tabular}

All the nouns in this subclass are Akan loanwords.

In Class IIb, the nouns carry the singular agreement prefix, $ə-/ a-$, in a word like $ə$-yisaa 'orphan'. Sentences (17a-17c) show that the agreement pattern with adjectives is similar to that of the preceding subclasses of nouns.

a. ə-yisaa a-kitibi.

SG-orphan SG-small

'small orphan.'

b. N-yisaa n-kitibi.

PL-orphan PL-small

'small orphans.'

c. Amo gyí n-kitibi.

3PL COP.be PL-small

'They are small.'

Table $4 \mathrm{~b}$ is a list of nouns in subclass IIb. 
Table 4b. $\quad$ o-/a-; N-

\begin{tabular}{|c|c|c|}
\hline Singular & Gloss & Plural \\
\hline क-yisaa & orphan & n-yisaa \\
\hline$a$-damfv & friend & $n$-damfv \\
\hline$a-k p \varepsilon \varepsilon b i$ & slave & $m$-kpecbi \\
\hline o-yirebi & child & $n$-yirebi \\
\hline o-bebu & proverb & $m$-bebu \\
\hline o-kura & village & $n$-kura \\
\hline$a-t a d I$ & dress & $n$-tadI \\
\hline
\end{tabular}

3.2.3 Class III. The distinguishing feature of nouns in nominal form class III is the plural agreement marker, $e$ - $/ \varepsilon$-. It has 3 subclasses. In subclass IIIa, the nouns do not have a singular prefix; in subclass IIIb, the nouns bear the singular prefix $o$ - $\%$. While nouns in IIIc also bear the singular prefix $o-/$, like nouns in subclasses IIIb they carry the suffix - $\varepsilon n \varepsilon$ in addition. Examples $(18 \mathrm{a}-\mathrm{c})$ show how adjectives agree with the noun in number.

Table 5 Class III

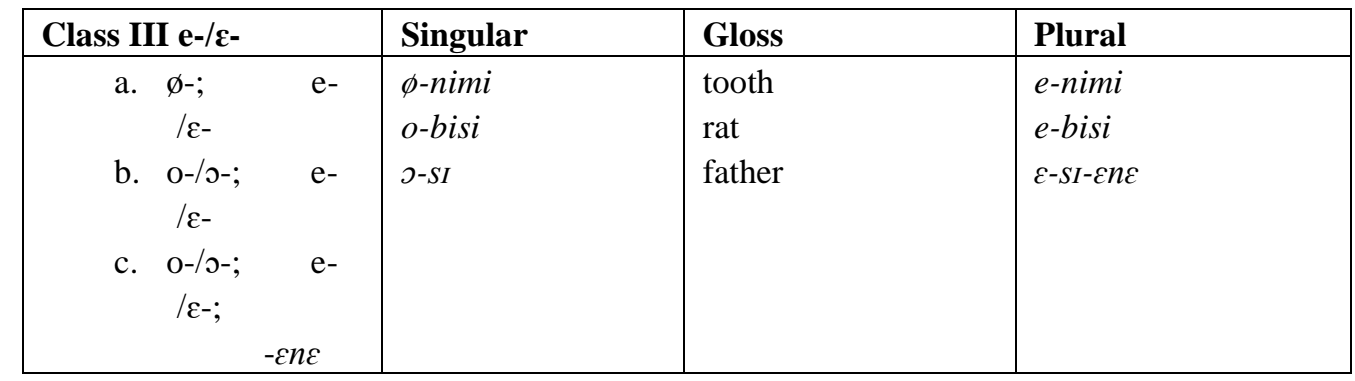

(18)

a. o-bisi a-kitibi a.

SG-rat SG-small DEF

'The small rat.'

b. o-bisi a gyí a-kitibi.

SG-rat DEF COP.be SG-small

'The rat is small.'

c. E-bisi n-kitibi a.

PL-bisi PL-small DEF

'The small mice.'

The examples indicate that there is number agreement between nouns in the class and adjectives. The majority of the nouns are animate nouns. 
Table 5 Nominal form class III (b) SG; PL prefixes o-/o; e-/ $\varepsilon-$

\begin{tabular}{|l|l|l|}
\hline Singular & Gloss & Plural \\
\hline o-nyine & man & $e$-nyine \\
\hline -tsl & woman & $\varepsilon$-tsl \\
\hline -lotsl & grandparent & $\varepsilon$-lotsl \\
\hline o-bitcw & uncle & $e$-bitcw \\
\hline o-birehu & neighbor & $e$-birehu \\
\hline$o$-foe & stranger & $e$-foe \\
\hline -taw & enemy & $\varepsilon$-taw \\
\hline$o$-yuw & thief & $e$-yuw \\
\hline$o$-bisi & mouse & $e$-bisi \\
\hline
\end{tabular}

3.2.4 Class IV. Nominal form class IV, the final class, is populated by nouns which bear the plural one, $a$-. Unlike the other classes we have discussed, this one is not divided into subclasses because it has only one realization in the singular; its singular prefix is 2 -. Class IV is mainly constituted by Akan loanwords, with nouns that predominantly denote animals. As with all the preceding classes, adjectives agree with nouns in this class in number. This is illustrated in $(19 \mathrm{a}-19 \mathrm{c})$. Table 6 is a list of nouns that belong to class IV.

a. o-kori o-fufuru o-kv.

SG-eagle SG-white SG-INDEF

'a white eagle.'

b. o-kori a gyí o-fufuru .

SG-eagle DEF COP.be SG-white

'the eagle is white.'

c. a-kori e-fufuru n-ko.

PL-eagle PL-white PL-INDEF

'Some white eagles.'

Table 6 Nominal form class IV SG/PL prefixes o-; a-

\begin{tabular}{|c|c|c|}
\hline Singular & Gloss & Plural \\
\hline o-kJmfv & fetish priest & $a-k J m f v$ \\
\hline o-bayifo & witch & a-bayifv \\
\hline o-sraani & soldier & a-sraafo \\
\hline o-ponks & horse & a-ponks \\
\hline o-sıbs & leopard & $a-s i b s$ \\
\hline o-korl & eagle & $a-k o r l$ \\
\hline o-kots & crab & $a-k o t s$ \\
\hline o-denkycm & crocodile & $a-d \varepsilon n k y \varepsilon m$ \\
\hline o-kra & soul & $a-k r a$ \\
\hline
\end{tabular}


3.3 Summary. These affixes used to express singular and plural and the ways in which they are paired is schematized in Fig. 1. It shows that Leteh displays parallel, convergent and crossed mapping.

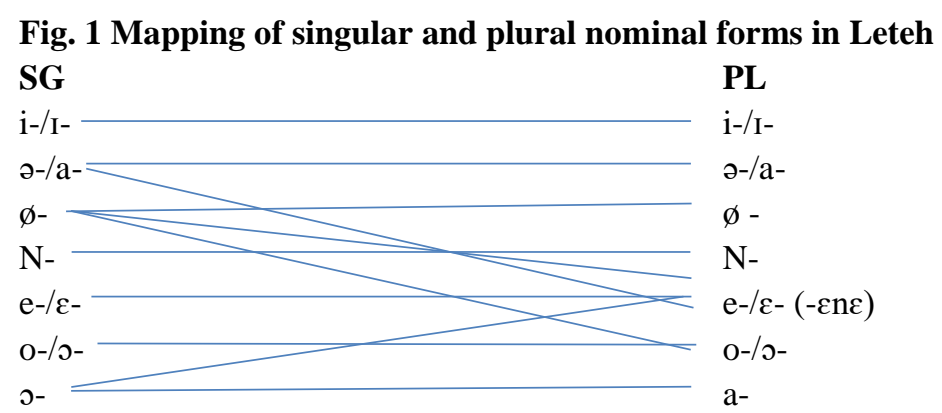

\section{Conclusion}

The paper has described Leteh nominal morphology in light of two phenomena: number marking and noun classification. Leteh is largely prefixal; the only suffix occurring with nouns is that which marks plural kinship and social relations terms. With respect to plural formation, Leteh nouns may be broadly categorized into two. Members belonging to the first group do not receive number marking, whereas with the second group, singular prefixes are replaced by plural prefixes. In this paper, nouns were classified based on number agreement patterns. Based on plural affixes, nouns were put into 4 broad nominal form classes, and after singular and plural pairing within each of the 4 classes, 11 classes were obtained. Akin to a number of Kwa languages, data for this paper show that about fifty percent of the nouns present invariant forms for singular and plural. For such nouns, although the adjectival modifiers may be marked for number, the head noun remains morphologically stable. There is also no sign of verbal concord. It is therefore number which triggers agreement. From the foregoing, it has been demonstrated that each of the 4 nominal form classes can be distinguished based on agreement of attributive and predicative adjectives. Furthermore, the sub-classification is done by the way plurality is marked.

There is indication of the loss of nominal prefixes. Similar to many other Kwa languages, the Leteh nominal form class system may therefore be described as vestigial. This is because there are discrepancies in the concordial relationships between nouns and their modifiers. Within a Leteh noun phrase, affixes that occur on the head and the modifiers show agreement in number but not in class; class concord is therefore missing. This paper shows that Leteh, a Guan language possesses nominal form classes, but not a concordial agreement system.

$\begin{array}{ll}\text { Abbreviations } \\ \text { COP } & \text { copula } \\ \text { DEF } & \text { definite } \\ \text { DEM } & \text { demonstrative } \\ \text { INDEF } & \text { indefinite } \\ \text { PL } & \text { plural } \\ \text { POSS } & \text { possessive } \\ \text { PERF } & \text { perfect }\end{array}$




$\begin{array}{ll}\text { PRES } & \text { present } \\ \text { PROG } & \text { progressive } \\ \text { PST } & \text { past } \\ \text { SG } & \text { singular }\end{array}$

\section{Reference}

Agbetsoamedo, Yvonne. 2014. Aspects of the Grammar and Lexicon of Seleq. Unpublished Ph. D. Thesis. Department of Linguistics, University of Stockholm.

Akrofi Ansah, Mercy. 2009. Aspects of Leteh (Larteh) Grammar. Unpublished Ph.D. Thesis. The University of Manchester. UK.

Akrofi Ansah, Mercy. 2012a. Compound formation in Lete (Larteh) . The Journal of West African Languages. Vol. XXXIX No. 2. 115-124.

Akrofi Ansah, Mercy. 2012b. Action nominalization in Leteh. Ghana Journal of Linguistics. Vol. 1 No. I: 3-13.

Akrofi Ansah, Mercy. 2013. Expressing Property concepts in Leteh (Larteh). Ghana Journal of Linguistics 2: 2, 23-40.

Akrofi Ansah, Mercy. 2014. The Morphosyntax of the Leteh Simple Noun Phrase. California Linguistics Notes. Vol. XXX1X No. 1 pp. 0-21. ISSN 15481484.

Bodomo, Adams and Charles Marfo. 2006. The Morphophonology of Noun Classes in Dagaare and Akan. Studi Linguistici e Filologici Online 4 (2). 2005-243.

Casali, Roderic, F. 1995. An overview of the Nawuri Verbal System. Journal of West African Languages. XX.1: 63-86.

Corbett, Greville G. 2007. Gender and Noun Classes. In Timothy Shopen (ed.) Language Typology and Syntactic Description. 3: 241-279.

Demuth, K. 2000. Bantu noun class systems: Loan word and acquisition evidence of semantic productivity. In G. Senft (ed.). Classification Systems. Cambridge University Press. 270-292.

Dixon, Robert Malcom W. 2010. Basic Linguistic Theory Vol. 1. Methodology. Oxford: Oxford University Press.

Dryer, Matthew. 2006. Descriptive Theories, Explanatory Theories, and Basic Linguistic Theory. In Felix Ameka, Alan Dench and Nicholas Evans (eds.) Catching Language. The Standing Challenge of Grammar Writing. 207-234. Mouton de Gruyter.

Eberhard, David M., Gary F. Simons and Charles D. Fennig (eds.). 2019. Ethnologue: Languages of the World. Twenty-second edition. Dallas, Texas: SIL International.

Essegbey, James. 2009. Noun classes in Tutrugbu. Journal of West African Languages. 36 (1 \& 2): 23-44.

Güldemann, Tom and Ines Fiedler. 2019. Niger-Congo "noun classes" conflate gender with deriflection. In Francesca Di Garbo, Bruno Olsson and Bernhard Wälchli (eds.). Grammatical Gender and Linguistic Complexity. Vol. 1: General issues and specific studies. Studies in diversity Linguistics. 96-145. Language Science Press.

Konoshenko, Maria and Dasha Shavarina. 2019. A Microtypological Survey of Noun Classes in Kwa. Journal of African Languages and Linguistics 40 (1): 75-114.

Osam, E. Kwaku. 1993. The loss of the Noun class system in Akan. Acta Linguistica Hafniensia 26. 81-106.

Osam, E. Kwaku. 1994. Aspects of Akan Grammar. Ph. D. Thesis. University of Oregon.

Painter, Colin. 1970. Gonja- A Phonological and Grammatical Study. The Hague: Mouton. 
Schuh, Russel G. 1995. Avatime Noun Classes and Concord. Studies in African Linguistics 24 (2) 123-149.

Snider, Keith. 1988. The Noun class system of Proto-Guan and its implications for internal classification. Journal of African Languages and Linguistics. 10 (2), 137-164.

Snider, Keith and James Roberts. 2004. SIL Comparative African Word lists (SILCAWL). Journal of West African Languages, Language Assessment.

Mercy Akrofi Ansah

Institute of African Studies

University of Ghana

Legon. Ghana. 